\title{
Psychosocial health challenges of the elderly in Nigeria: a narrative review.
}

\author{
Victor J Animasahun ${ }^{1,2}$, Helena J Chapman ${ }^{3}$
}

1. Faculty of Clinical Sciences, Obafemi Awolowo College of Health Sciences, Olabisi Onabanjo University, Sagamu, Ogun State, Nigeria.

2. Lagos State University Teaching Hospital, Lagos, Nigeria.

3. Department of Environmental and Global Health, University of Florida, Gainesville, Florida, USA.

\begin{abstract}
Background: Globally, national health systems are challenged to build successful aging models to prepare for biomedical, psychological and social changes. The integral component of psychosocial health in overall quality of life and well-being, however, is underscored and requires greater focus. Changing demographics in Nigeria, in addition to cultural considerations and absence of a social security system, present unique challenges to elderly.

Objective: We aimed to review the literature that describes the current situation and challenges in psychosocial health status in the elderly in Nigeria and provide recommendations that promote health and well-being during the aging process.

Results: Four primary factors affect psychosocial health status of elderly Nigerians, namely: changes in family dynamics, increased demand for healthcare services, increased economic stress, and decreased functional independence.

Conclusion: Like other developing countries, the Nigerian national system faces similar challenges in preparing a national framework that can maximize coverage to citizens in the midst of demographic changes in aging. By focusing on five target areas such as the educational system, health services, community-based initiatives, local or regional policies and national strategies, current framework in Nigeria can be modified to prepare for changing demographics in aging.
\end{abstract}

Keywords: Aging, family support, Nigeria, psychosocial.

DOI: https://dx.doi.org/10.4314/ahs.v17i2.35

Cite as: Animasabun VJ, Chapman HJ. Psychosocial health challenges of the elderly in Nigeria: a narrative review. Afri Health Sci. 2017;17(2): 575-583. https://dx.doi.org/10.4314/abs.v17i2.35

\section{Introduction}

Globally, demographic patterns across all nations have changed considerably over the past century, recognized as an achievement for humanity. ${ }^{1}$ Factors, such as decreased mortality rates, decreased birth rates, and migration trends, contribute to changes in population structure, and thus, can be directly related to population aging. ${ }^{2}$ Defin-

\section{Corresponding author:}

Victor J Animasahun,

Faculty of Clinical Sciences, Obafemi Awolowo

College of Health Sciences, Olabisi Onabanjo

University, Sagamu, Ogun State, Nigeria.

Lagos State University Teaching Hospital, Lagos,

Nigeria.

Tel+2348053354024

Email: drvictorani@gmail.com ing 'older' persons, however, has been challenging across low-, middle- and high-income nations, ${ }^{3}$ compelling the United Nations to establish the definition of 'older' persons as those persons over age 60 years. ${ }^{4}$ As the global population of older persons is estimated to increase from $11 \%$ in 2000 to $22 \%$ in $2050,{ }^{5}$ population aging will clearly transform all aspects of society, ranging from changes in economic security, employment opportunities, family structure, housing resources, and transportation services. ${ }^{6,7}$ This imminent transition poses the challenge of effective delivery of healthcare services to older persons. Therefore, appraisal of current health systems in developed and developing nations that promote health and well-being are key during the aging process.

Active aging describes the interaction among factors, such as maintenance of health and well-being, involvement in social activities, and overall security or protection, which promote optimal health and well-being during the aging process. ${ }^{1}$ Although multiple models of successful aging 
have targeted biomedical, social or psychological functioning, ${ }^{8}$ one popular model, albeit with limitations, remains the Rowe and Kahn model of successful aging, which interconnects three factors: avoidance of disease, active participation in life activities, and high levels of physical or cognitive function. ${ }^{9}$ However, the less dynamic nature of this model, ${ }^{8}$ in addition to the absence of the influence of psychological health, including positive spirituality, ${ }^{10}$ may not elucidate the true role of psychosocial health in successful aging.

Often described as an ambiguous term, psychosocial health represents the multiple, dynamic interactions between social and behavioral variables. ${ }^{11}$ The influence of these biological, psychological and social factors on the aging process can influence an individual's well-being, quality of life, and health outcomes. Self-rated quality of life among elderly persons extends beyond physical health, primarily focusing on the ability to independently perform activities of daily living (ADLs) or active social engagement. ${ }^{12}$ These constructs, however, reflect dynamic pathways that cannot be fully measured in a cross-sectional manner, which may challenge scientific or social inquiry. ${ }^{11}$

Nigeria, described as culturally and environmentally diverse, is a lower-middle income country in sub-Saharan Africa. ${ }^{13}$ It is currently the seventh largest country in the world, and with the fastest population growth, is projected to become the third largest. ${ }^{14}$ Figure 1 shows the estimates and projections of population size, from 1950 to 2050 , in Nigeria. ${ }^{15}$ Due to technological advancements in medicine and water, hygiene and sanitation measures, like other African nations, Nigeria reports a significant increase in survival for persons over age $60 .{ }^{16}$

Figure 2 shows the estimates and projections of the number of persons over age 60 , by general population and by sex, from 1950 to 2050, in Nigeria. ${ }^{15}$

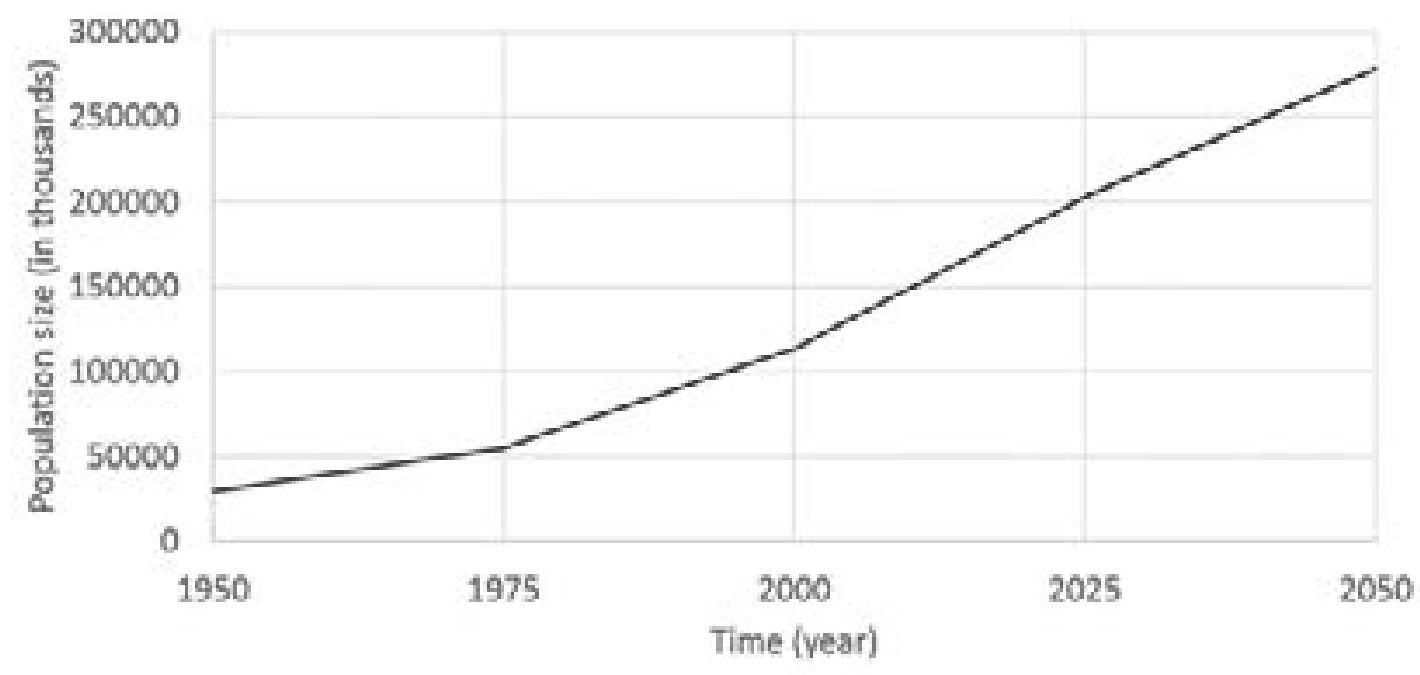

Figure 1. Estimates and projections of population size (in thousands) in Nigeria, 1950 to $2050 .^{15}$ 


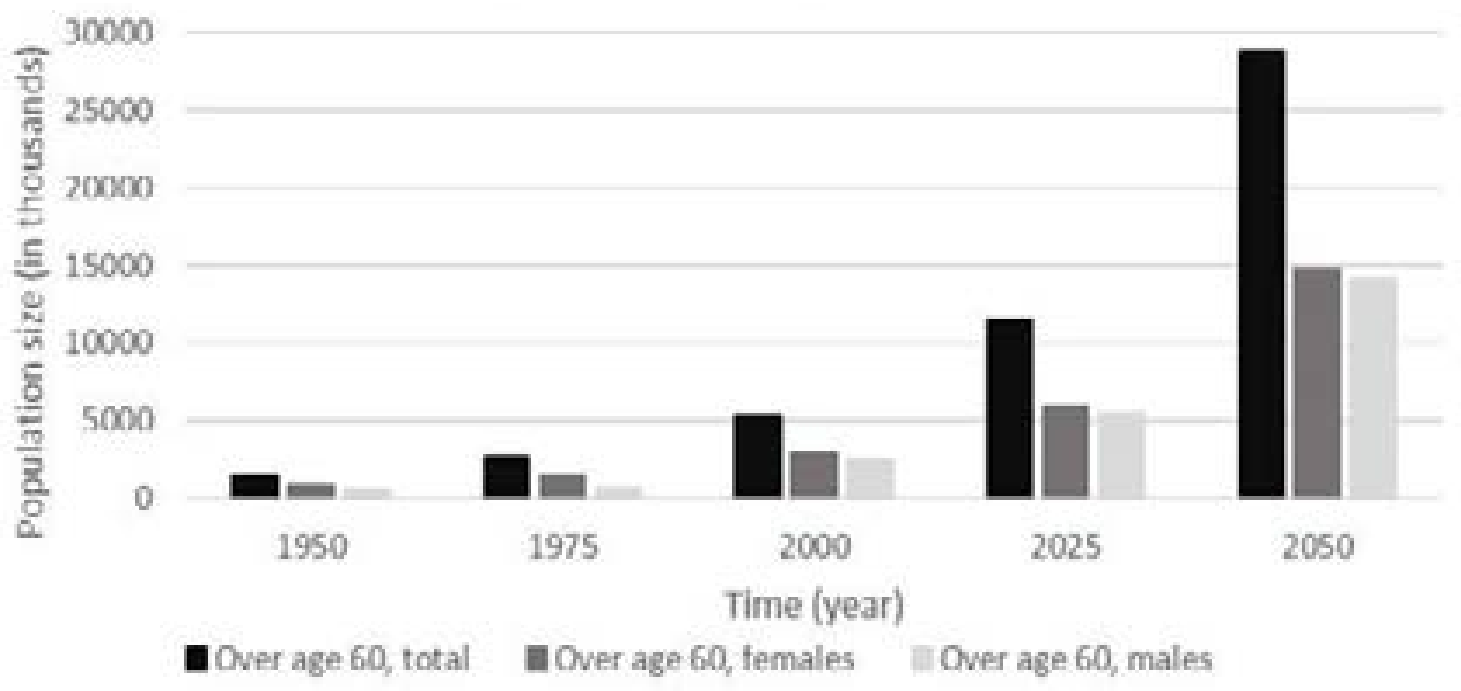

Figure 2. Estimates and projections of the number of persons over age 60 (in thousands), by general population and by sex, in Nigeria, 1950 to $2050 .^{15}$

Changing demographics in Nigeria, without a doubt, have presented several challenges that may influence the modification of federal regulations, health policies or social programs that promote physical and psychosocial health through active aging. First, traditional family structure, care giving inside the home, and security of older adults ${ }^{17,18}$ may influence cultural practices, especially in the context of the HIV/AIDS epidemic. ${ }^{19}$ Second, although increased longevity has been aided by advancements in medical diagnostics, technology and treatment, the delivery of healthcare services is crucial for the prevention of diseases, disabilities or other complications during the aging process. ${ }^{20}$ Third, just as in high-income countries, educational opportunities in gerontology or geriatrics at the technical, undergraduate or graduate levels have trailed behind other specialties ${ }^{21}$ and should receive greater attention to manage the health concerns of the aging population. ${ }^{22,23}$ Finally, since older persons do not receive social security ${ }^{24}$ federal support to older persons for economic independence may require foresight or revisions of political policies.

In Africa, however, the majority of studies that focus on psychosocial health in the elderly were from Nigeria and South Africa. Similar to Nigeria, the population growth of elderly in South Africa has increased, estimated from $6.6 \%$ in 2002 to $8.0 \%$ in $2016 .{ }^{25}$ Primary healthcare providers are challenged with teeming clinic attendance and usually unable to provide adequate healthcare, education and support services to older persons. ${ }^{26}$ South African elderly tend to be community residents, living in multiple generational family households, due to limited institutionalized care. ${ }^{27}$ However, unlike Nigerian elderly, South African elderly do receive financial support through the nationalized pension system. ${ }^{27}$ Thus, one observed pathway to stimulate initiatives focusing on active aging and optimal psychosocial health status for elderly can include the use of home-based, self-care guidelines. ${ }^{26}$ As such, in both Nigeria and South Africa, challenges related to population aging, such as psychosocial health status, remain a significant priority for future research and policy development.

Essential for continued population growth and social and economic advancement in Nigeria, this call to action for sustainable, intersectoral collaborations in active aging will be an important strategy for all nations. Even more, focusing on psychosocial health, rather than solely on physical health, will be key to assess models of successful aging. This report critically reviewed the literature that describes the current situation and challenges in psychosocial health status in Nigerian elderly and provided recommendations that may facilitate the promotion of health and well-being during the aging process.

\section{Methods}

A narrative review of the peer-reviewed literature was conducted to examine the research question: What are the driving factors for the psychosocial health challenges among the elderly in Nigeria? Authors searched three databases (PubMed, Google Scholar, African Journals Online), using terms "Nigeria" AND "psychosocial" AND

African Health Sciences Vol 17 Issue 2, June, 2017 
"health" AND (“elder” OR “elders” OR “elderly”) AND ("old" OR “older"), between years 2000 and 2015. We reviewed the reference lists of selected articles for additional articles on the topic. Relevant articles were reviewed and included in this review.

This review provides an overview or broad scope of the topic at hand, following guidelines described in previous publications. ${ }^{28,29}$ The findings serve as a useful educational tool for this critical public health issue. ${ }^{28}$ It is important to note, however, that the main limitation of narrative reviews lies in the unsystematic search method, which may lead to the subjective selection of articles and consequently add bias to the overall interpretation of findings. ${ }^{28,29}$ Authors considered this limitation in their search strategy, but with limited published evidence in the literature, they prioritized the need for an overview of this selected topic.

\section{Challenges in psychosocial health of elderly in Ni- geria}

Despite commendable global advancements in disease management and health promotion strategies, challenges in disability, declining cognition and maintaining social networks pose a nightmare to older persons and their families in Nigeria. Life-changing stressors or events, including gains or losses of material possessions or social networks, may contribute to social isolation or reduced perceptions of self-worth. In SouthWestern Nigeria, cultural values, gender, death of a spouse, and individual health status before age 60 were identified as significant determinants in psychosocial health status of an elderly person. ${ }^{30}$ For example, declining sexual activity or in- creased stress in older age may vary by sex. Older females may experience decreased libido due to emotional reactions after the death of her spouse, whereas older males may endure physiological sexual dysfunction. ${ }^{30}$ Also, since domestic chores are traditionally completed by females in the typical patriarchal society, the older female may feel pressure toward the completion of domestic duties, whereas the older male may experience stress and anxiety about financial security. ${ }^{30}$

Discrimination can be two-fold for the Nigerian elder who suffers from any mental health condition. First, co-morbidities in physical or psychological health may affect the ability of older persons to perform ADLs. Since a spectrum of mental health conditions are treated in rural or urban primary care centers, by staff without psychiatric training, diagnostic measures and chronic disease management may be inadequate. Second, stigma associated with mental illness can negatively affect the frequency of how elders seek medical services. Without appropriate identification of mental health conditions, including substance abuse, elders may experience poor quality of life or health outcomes due to disability, co-morbidities or chronic disease progression; increased stressors due to care giving or perceptions of decreased self-worth that may lead to suicide ideation or lack of will for survival. ${ }^{31}$

\section{Factors responsible for the psychosocial health chal- lenges among the elderly in Nigeria}

Elderly persons in Nigeria can face multiple challenges in maintaining their psychosocial health status. Figure 3 describes these challenges as changes in family dynamics, increased demand for healthcare services, increased economic stress, and decreased functional independence.

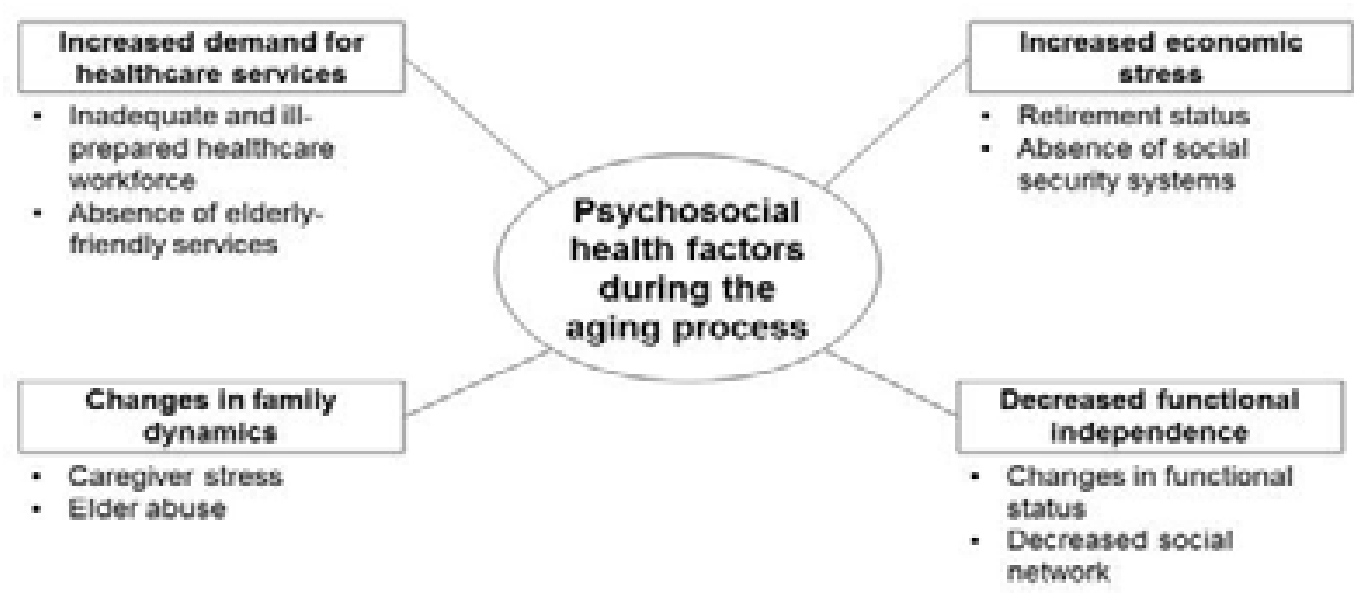

Figure 3. Psychosocial health factors faced by Nigerian elderly during the aging process. 


\section{Changes in family dynamics}

Caregiver stress. In Nigeria, family members play a significant role in care for elders, providing up to $90 \%$ of home care. Elderly care, seen in the form of institutionalized centers or private home care in some industrialized countries, is rarely seen in Nigeria. The 1989 Policy on Ageing by the Federal Ministry of Social Welfare emphasizes home care for the elderly by both family and healthcare workers to provide psychological support. ${ }^{32}$ As family caregivers devote their time to the elder's needs, they tend to neglect their own needs, and thus may face health risks. They may not recognize or may ignore signs of illness, exhaustion or depression. Stress may negatively impact physical health of the caregiver or cause the caregiver to be physically or verbally aggressive towards the elderly person, leading to elderly abuse or neglect. In addition, caregivers may frequently feel a wave of emotions, such as anger, anxiety, depression, diminished social activities, frustration, guilt, isolation, marriage dissatisfaction, or decreased self-esteem. ${ }^{33}$

Elderly abuse. In Nigeria, although elderly abuse exists, prevalence rates are unknown. ${ }^{16}$ Nigerian family values premised on love and empathy are gradually being replaced by materialism and abandonment, which account for insecurity as well as increased physical or psychological abuse or neglect of elderly. ${ }^{16}$ One study conducted in Akwa Ibom State, Nigeria, reported a high prevalence of elder abuse, where $46.7 \%$ of elders complained of medical neglect and bed sores; $47 \%$ experienced some form of physical abuse; $44.7 \%$ reported lack of visitation; $49 \%$ were uncomfortable with their living conditions; and 35\% were victims of theft. ${ }^{34}$ Another study among elders in Enugu State, Nigeria, documented a high prevalence of denial of freedom of interaction (88\%) and verbal abuse $(73 \%) .{ }^{35}$ Gender imbalance may hold important implications for social support and public planning as older women experience more social challenges and domestic violence than older men. Also, compared to men, they are more likely to experience discrimination in access to inheritances, social security measures, and political power and health. As a result of these cumulative disadvantages, women are more likely to be financially under-resourced and more susceptible to endure psychosocial health challenges in older age than their male counterparts. ${ }^{34-36}$

\section{Increased demand for healthcare services}

Elderly persons tend to be significant users of medical services, due to the need to monitor acute or chronic changes in physical, social and psychological function. In Nigeria, access to healthcare is severely limited both by paucity of health facilities and manpower and by out-ofpocket payment arrangement. ${ }^{37}$ In fact, in sub-Saharan Africa, barriers to healthcare faced by older people have included elevated medical costs related to transportation to the health center as well as disease management, minimal number of specialized centers for care, and lack of programs to optimize culturally- and age-sensitive care at federal health centers. ${ }^{38}$ Geriatric medical services are not prioritized in the Nigerian health system, which has been observed due to lengthy waiting time for healthcare appointments, low provider-patient ratio, and poor communication among elders and their healthcare providers, which may lead to unwillingness to utilize health services. ${ }^{37}$

\section{Increased economic stress}

Retirement. Since poverty remains a major challenge in Nigeria, elderly persons, who have retired from the economic productive phase, are most vulnerable to experiencing economic hardship. Since the statutory age of retirement in Nigeria is the cut-off for being categorized as an elderly person, majority of these group of people are not socially and economically secure. ${ }^{18,39}$ Elderly people are usually faced to cope with the paradox of dwindling financial resources, increased health challenges and a geometric rise in medical expenses. In particular, elderly people living in Edo Central, Nigeria, reportedly utilized health services when they were available, accessible and affordable. $^{20}$

The patterns of the economic lives of older persons in Nigeria vary by urban and rural residences. ${ }^{39}$ In urban Nigeria, elders with high physical and psychological functioning are forced to retire once they reach the retirement age. They face abrupt declines in their income and can feel less self-worth or even depression since they perceive themselves as being fit to work. However, in rural Nigeria, since many older persons are not formally employed with a company, they continue to engage in mental and manual work with meager earnings as long as their physical strength can afford. The rural elderly may suffer from stress disorders, physical exhaustion with no retirement benefits.

Absence of social security systems. Provision of social services, such as income security, healthcare, housing and legal assistance, positively influence the psychosocial African Health Sciences Vol 17 Issue 2, June, 2017 
health of elderly. ${ }^{18}$ However, there is absence of national social security to provide economic buffer in older age. ${ }^{40}$ In 1989, the Nigerian government developed the National Social Development Policy which aimed to provide a framework for protecting elderly persons from moral and material neglect and provide public assistance when necessary. Despite adequate provisions, however, there has been no effective execution by any federal agency. ${ }^{18}$ In addition, although regional levels have demonstrated presence of policy frameworks for the elderly, policy changes have not been observed in Nigeria. ${ }^{16}$ The failure of the Nigerian federal institutions to regularly disburse pension funds to retirees and provide adequate social services for the aged pose a significant threat to food security, social security and national security. ${ }^{17}$

\section{Decreased functional independence}

Quality of social support and participation in community activities are important predictors of positive psychosocial quality of life among respondents in Ibadan, Nigeria. ${ }^{41}$ In Lagos, Nigeria, experience and severity of depression were found to be significantly related to overall social support. ${ }^{42}$ Social support can originate from family and friends as well as membership to community or faithbased organizations. Although socio-demographic status had no significant relationship with social support, social support reportedly decreased with increasing age, due to loss of a spouse, residence in a particular community for less than 10 years, low income, retirement status, or/ and minimal participation in faith-based activities. ${ }^{42}$ However, active participation in community organizations was significantly associated with high social support. ${ }^{42}$ Social network dwindles and traditional family support decreas- es since younger family members migrate to urban settings for educational and employment opportunities. ${ }^{40,43}$ Factors, such as increasing social network, support and engagement, are increasingly more significant for elderly as social changes affect the structure of the traditional extended family and economic pressures lead to family members leaving for the cities. ${ }^{41}$ Cumulatively, these social factors may affect the well-being of elderly persons even more so than health-related factors. ${ }^{41}$

\section{Recommendations}

With the future outlook for changing demographics across Nigeria, as the globe, our local and national leaders should promote clear changes in our policy to prepare Nigeria for any challenges. Table 1 presents the recommendations for optimal psychosocial health during the aging process of Nigerian elderly. First, the educational system can develop age-appropriate training protocols for children, adolescents and young adults about challenges associated with the physical and psychosocial processes of aging. They should be encouraged to prepare mentally and financially for their retirement through savings, investments and insurance schemes so that they can reduce caregiver burden. Second, health services can add health promotion activities to educate and empower elderly persons to improve their confidence about healthy behaviors during the aging process. Through adequate nutritional intake, lifestyle modifications to incorporate physical activity, and reduction of toxic habits such as tobacco use or excess alcohol consumption, healthcare expenditures can be reduced. These health promotions for regular medical evaluations may influence positive health-seeking behaviors.

Table 1. Recommendations for optimal psychosocial health during the aging process in Nigeria

\begin{tabular}{|l|l|}
\hline Target & Recommendation \\
\hline Educational system & $\begin{array}{l}\text { To train children, adolescents and young adults about } \\
\text { physical and psychosocial processes of aging. }\end{array}$ \\
\hline Health services & $\begin{array}{l}\text { To develop health promotion activities that empower } \\
\text { elderly about healthy behaviors during the aging process. }\end{array}$ \\
\hline Community-based initiatives & $\begin{array}{l}\text { To organize family-oriented activities (e.g, recreational, } \\
\text { social, educational) that emphasize family support as an } \\
\text { integral component. }\end{array}$ \\
\hline Local or regional policies & $\begin{array}{l}\text { To promote intersectoral collaboration and } \\
\text { multidisciplinary approaches that engage elderly in } \\
\text { physical, psychological and social activities in their } \\
\text { community. }\end{array}$ \\
\hline National strategies & $\begin{array}{l}\text { To integrate appropriate mechanisms into mainstream } \\
\text { planning for research, social programs and economic } \\
\text { policies. }\end{array}$ \\
\hline
\end{tabular}


Third, community-based initiatives can focus on family-oriented activities, such as recreational, social or educational, to emphasize the integral component of family support in the aging process. Activities can provide strategies on how to face inter-generational conflicts. Faith-based and non-governmental organizations are fundamental sources in providing educational programs, gratuitous medical evaluations, and social support strategies that can reduce the burden of health challenges of Nigerian elderly. Fourth, local or regional policies can promote intersectoral collaboration and multidisciplinary approaches to engage elderly persons in physical, psychological and social activities. By using a holistic approach, appropriate activity levels can be matched to the health status and independence level of the elderly. Communities should have access to resources or technical assistance related to water and sanitation, housing, transportation, and health promotion and disease prevention strategies. Concerted efforts must be in place to mitigate poverty and negative effects associated with the aging process.

Finally, national strategies must deliberately integrate appropriate support mechanisms for older persons into the mainstream of their social and economic planning based on the principle of equity and social justice. By considering the unique needs of older persons, comprehensive descriptions of national policies can clearly outline how leaders aim to incorporate challenges for employment, healthcare, transport, housing and social care for older citizens. Research, planning and policy implementation at the national level is timely and imperative to pave the future path to optimal health in older Nigerian citizens.

\section{Conclusion}

In Nigeria, older persons and their families face challenges in coping with functional physical and psychosocial health status of the aging process. These factors include changes in family dynamics, increased demand for medical services, increased economic stress, and decreased functional independence. An element of age-related exclusion exists in Nigerian health systems which fails to focus attention on the older population, including risk of family neglect or poverty. By focusing on five target areas ie, educational system, health services, community-based initiatives, local or regional policies and national strategies, we can advance the current framework in Nigeria and prepare our country for changing demographics in aging.

\section{Conflict of interests}

The authors declare that they have no conflicts of interest.

\section{Funding}

None.
Abbreviations
ADL $=$ Activities of daily living
AIDS = Acquired Immunodeficiency Syndrome
HIV $=$ Human Immunodeficiency Virus

\section{Acknowledgements}

None.

\section{References}

1. World Health Organization. Active ageing: a policy framework [Internet]. Geneva: World Health Organization; 2002 [cited 2016 Aug 31]. Report No.: WHO/ $\mathrm{NMH} / \mathrm{NPH} / 02.8$. Available from: http://www.who.int/ ageing/publications/active_ageing/en/

2. Bloom DE, Luca DL. The global demography of aging: facts, explanations, future. In: Piggott J, Woodland A, editors. Handbook of the economics of population aging. Oxford: Elsevier, 2016. p. 3-56.

3. World Health Organization. Proposed working definition of an older person in Africa for the MDS project [Internet]. Geneva: World Health Organization; 2016 [cited 2016 Nov 27]. Available from: http://www.who. int/healthinfo/survey/ageingdefnolder/en/

4. United Nations. World population ageing 2013 [Internet]. New York: United Nations; 2013 [cited 2016 Aug 31]. Available from:http://www.un.org/en/development/desa/population/publications/pdf/ageing/ WorldPopulationAgeing2013.pdf

5. World Health Organization. Facts about ageing [Internet]. Geneva: World Health Organization; 2014 [cited 2016 Aug 31]. Available from: http://www.who.int/ageing/about/facts/en/

6. United Nations, Department of Economic and Social Affairs, Population Division. World population ageing 2015 [Internet]. New York: United Nations; 2015 [cited 2016 Aug 31]. Report No.: ST/ESA/SER.A/390. Available from: http://www.un.org/en/development/desa/ population/publications/pdf/ageing/WPA2015_Report.pdf

7. World Health Organization; National Institutes on Aging; National Institutes of Health. Global health and age- 
ing [Internet]. Bethesda: National Institutes of Health; 2011 [cited 2016 Aug 31]. Report No.: NIH 11-7737. Available from: http://www.who.int/ageing/publications/global_health/en/

8. Bowling A. Aspirations for older age in the 21 st century: what is successful aging? Int J Aging Hum Dev. 2007 Apr;64(3):263-97.

9. Rowe JW, Kahn RL. Successful aging. Gerontologist. 1997 Aug;37(4):433-40.

10. Crowther MR, Parker MW, Achenbaum WA, Larimore WL, Koenig HG. Rowe and Kahn's model of successful aging revisited: positive spirituality - the forgotten factor. Gerontologist. 2002 Oct;42(5):613-20.

11. Martikainen P, Bartley M, Lahelma E. Psychosocial determinants of health in social epidemiology. Int J Epidemiol. 2002 Dec;31(6):1091-3.

12. Sander M, Oxlund B, Jespersen A, Krasnik A, Mortensen EL, Westendorp RG, et al. The challenges of human population ageing. Age Ageing. 2015 Mar;44(2):1857.

13. The World Bank. Nigeria [Internet]. Washington DC: The World Bank; 2015 [cited 2016 Aug 31]. Available from: http://data.worldbank.org/country/nigeria

14. United Nations, Department of Economic and Social Affairs, Population Division. World population prospects: the 2015 revision. Key findings and advance tables [Internet]. New York: United Nations; 2015 [cited 2016 Aug 31]. Report No.: ESA/P/WP.241. Available from: http://esa.un.org/unpd/wpp/publications/files/key_ findings_wpp_2015.pdf

15. United Nations, Department of Economic and Social Affairs, Population Division. World population ageing 1950-2050 [Internet]. New York: United Nations; 2002 [cited 2016 Aug 31]. Report No.: ST/ESA/SER.A/207. Available from: http://www.un.org/esa/population/ publications/worldageing19502050/

16. Mudiare PE. Abuse of the aged in Nigeria: elders also cry. American International Journal of Contemporary Research. 2013 Sep;3(9):79-87.

17. Ajomale O. Country report: ageing in Nigeria - current state, social and economic implications. Summer Newsletter 2007 of the Research Committee (RC11) on the Sociology of Ageing of the International Sociological Association (ISA). 2007 Summer:15-20.

18. Oladeji D. Family care, social services, and living arrangements factors influencing psychosocial well-being of elderly from selected households in Ibadan, Nigeria. Education Research International. 2011:1-6.

19. Nabalamba A, Chikoko M. Aging population challenges in Africa. African Development Bank. 2011 Nov;1(1):1-19.

20. Odaman MO, Ibiezugbe MI. Health seeking behavior among the elderly in Edo Central Nigeria. International Review of Social Sciences and Humanities. 2014; 7(1):201-10.

21. Bardach SH, Rowles GD. Geriatric education in the health professions: are we making progress? Gerontologist. 2012 Oct;52(5):607-18.

22. Iloh G, Amadi AN, Awa-Madu J. Common geriatric emergencies in a rural hospital in south-east Nigeria. Niger J Clin Pract. 2012 Jul-Sep;15(3):333-7.

23. Olayiwola IO, Oganah BC, Ojo TG, Akande TO. Knowledge of population ageing and elderly nutrition among undergraduates in a Nigerian university. International Journal of Education and Research. 2013 Aug;1(8):1-12. 24. Idris SH, Ibrahim MJ, Sufiyan MB, Oladipo IA. Health problems and pattern of care for elderly people in rural Nigeria. Asian J Gerontol Geriatr. 2012 Dec;7(2):115. 25. Statistics South Africa. Mid-year population estimates 2016 [Internet]. Pretoria: Statistics South Africa; 2016 [cited 2016 Nov 6]. Report No.: P0302. Available from: http://www.statssa.gov.za/publications/P0302/ P03022016.pdf

26. Rabie T, Klopper HC. Guidelines to facilitate self-care among older persons in South Africa. Health SA Gesondheid. 2015 Jun;20(1):33-44.

27. Charlton KE, Rose D. Nutrition among older adults in Africa: the situation at the beginning of the millennium. J Nutr. 2001 Sep;131(9):2424S-8S.

28. Green BN, Johnson CD, Adams A. Writing narrative literature reviews for peer-reviewed journals: secrets of the trade. J Chiropr Med. 2006 Fall;5(3):101-17.

29. Ferrari R. Writing narrative style literature reviews. Medical Writing. 2015; 24(4):230-5. PubMed

30. Akinyemi A, Aransiola J. Gender perspectives in self-assessment of quality of life of the elderly in south-western Nigeria: are there variations in quality of life among ageing men and women? Journal of Comparative Research in Anthropology and Sociology. 2010 Spr;1(1):107-20. 31. Nicholls A. Assessing the mental health needs of older people [Internet]. London: Social Care Institute for Excellence; 2006 [cited 2016 Aug 31]. Available from: http://www.scie.org.uk/publications/guides/guide03/ 
32. Awosika GO, Odunbaku SO, Olley B, Baiyewu O. Supporting caregivers of elderly Nigerian patients with dementia: the experience of the Ibadan Dementia Research Project. IPA Bulletin [Internet]. 2003 [cited 2016
Aug 31]. Available from: http://psychiatry.medicine. iu.edu/index.php/download_file/view/1175/712/

33. Okoye UO, Asa SS. Caregiving and stress: experience of people taking care of elderly relations in south-eastern Nigeria. Arts and Social Sciences Journal. 2011 Jun:2011(29):19. 